\title{
Metrological support of measurements in brachytherapy
}

A. Y. Villevalde, A. V. Oborin, S. G. Trofimchuk

D. I. Mendeleyev Institute for Metrology (VNIIM)

190005, Moskovsky pr., 19, St. Petersburg, Russia, Tel.: +7(812)323-9613, E-mail: vay@vniim.ru

Abstract: The elements of metrological support of measurements in brachytherapy are considered. Measurements of air-kerma strength from iridium-192 and iodine-125 brachytherapy sources and well-type ionization chambers calibration with these sources are described.

\section{Problem description in general and its connection with significant scientific and practical tasks}

The most demanding requirements to the accuracy of measurements in dosimetry at present are set by medicine and radiotherapy in particular. Brachytherapy is an advanced and fast emerging form of radiotherapy, where a sealed radiation source is placed inside or next to the area requiring treatment permanently or temporary.

Efficiency of brachytherapy is straightly connected to the precision of the dose delivered to the patient. The requirements for the accuracy of dose measurement are stated in Russian and international standards: the uncertainty of patient's dose should be less than $\pm 5 \%$ [1-4]. To fulfill these requirements it is necessary to take into account many aspects, but it has generally been recognized that use of radiation sources with accurately measured characteristics and traceability of these measurements to the national standards are essential [5-7]. The relevant issues are of current interest.

\section{Analysis of recent research and publications connected to the problem solving. Problem solution in general}

The characteristics of radiation sources for brachytherapy are normally measured in clinics by the dosimeters with well-type ionization chambers [8]. For the traceability assurance these dosimeters have to pass calibration or verification procedures. Such dosimeters are usually calibrated in terms of the quantities derived from air kerma.

According to the recommendations of American Association of Physicists in Medicine (AAPM) the basic quantity for radiation measurement from medical sources in North America is air-kerma strength, $S_{K}$, with units $\mu \mathrm{Gy} \cdot \mathrm{m}^{2} \cdot \mathrm{h}^{-1}$ [6]. $S_{K}$ is defined as the product of the airkerma rate $\dot{K}_{a v}$ at a point in free space (vacuum) located in the transverse bisecting plane at a distance $d$ from the center of the source, and the square of the distance $d: S_{K}=\dot{K}_{a v}(d) \cdot d^{2}$. The distance $d$ should be large enough that the source may be treated as a mathematical point.

The corresponding quantity applied in European countries and proposed by International Commission on Radiation Units and Measurements (ICRU) is reference airkerma rate, $\dot{K}_{\delta}$, with units $\mu \mathrm{Gy} \cdot \mathrm{h}^{-1}[9] . \dot{K}_{\delta}$ is specified as the air-kerma rate in vacuum due to photons of energy greater than the stated value, at a point located at reference distance $d_{r e f}$. The reference distance is usually specified as $1 \mathrm{~m}$, in which case air-kerma strength and reference air-kerma rate would have the same numerical value, although formally with different units.

There are several primary standards in dosimetry of iridium-192 and iodine-125 radiation sources for brachytherapy (the USA, Germany, Italy [10-13]). The expanded uncertainty of $S_{K}$ (or $\dot{K}_{\delta}$ ) is from $1,8 \%$ to $2,0 \%$ for these primary standards [10-12]. In Russia such a primary standard is not yet developed therefore the measuring instruments traceable to the national primary standard for x-rays and gamma radiation air-kerma GET 82011 are used for measurements with brachytherapy sources [14]. Similar approach is implemented in several national metrology instruments, for example at the NPL (the UK) with the expanded uncertainty of $\dot{K}_{\delta} 5,6 \%$ [15]. 


\section{Objective of research and its tasks}

The objective of the research conducted by the VNIIM dosimetry laboratory is to develop the system of metrological support of measurements with iridium-192 and iodine-125 sources for brachytherapy. At the first step the procedures of air-kerma strength measurement from iridium-192 and iodine-125 brachytherapy sources were developed. According to these procedures the measuring instruments were chosen and prepared for the measurements. Then practical measurements with high dose rate iridium-192 and low dose rate iodine-125 seed sources were performed by these procedures. Finally calibration of well-type ionization chambers with electrometers was done using the sources with measured air-kerma strength.

\section{Main research material and results explanation}

Air-kerma strength measurement from iridium-192 brachytherapy sources was performed using the spherical ionization chamber of type TM32005 with measuring volume $30 \mathrm{~cm}^{3}$. TM32005 chamber calibration coefficient for iridium-192 was produced by linear interpolation of its calibration coefficient for CCRI 250 radiation quality with effective energy $124 \mathrm{keV}$ received at the medium energy $\mathrm{x}$-rays radiation facility and its calibration coefficient for Cs-137 source received at gamma-radiation facility (both facilities are from the structure of GET 8-2011 standard).

The measurements with iridium-192 brachytherapy sources were performed in free space at more than $1,5 \mathrm{~m}$ distance from the floor, walls, ceiling and other objects that can cause radiation scattering. The measurements were performed at five distances between the source and the chamber from 20 to $100 \mathrm{~cm}$. Each measured value was corrected for attenuation and scattering of radiation in air. The mean of measured values was taken as a result of air-kerma strength measurement.

Air-kerma strength from iridium-192 brachytherapy sources was calculated using the following expression: $S_{K}=N_{K} \cdot I \cdot d^{2} \cdot k_{\rho} \cdot k_{a t} \cdot k_{s c} \cdot k_{r n} \cdot k_{a n} \cdot k_{s a t} \cdot k_{d}$, where $N_{K}$ is the ionization chamber calibration coefficient for iridium-192, $\mu \mathrm{Gy} / \mathrm{C}$; $I$ is the mean ionization current of the chamber, $A ; d$ is the distance from the center of the chamber to the center of the active part of the source, $\mathrm{m} ; k_{\rho}$ is the correction for the difference between the air density during the measurements and under the reference conditions; $k_{a t}$ is the correction for air-attenuation; $k_{s c}$ is the correction for scattering; $k_{r n}$ is the correction for radial nonuniformity; $k_{a n}$ is the correction for the source anisotropy; $k_{\text {sat }}$ is the correction for saturation; $k_{d}$ is the correction for the decay of iridium-192 during the time of measurements.

Air-kerma strength measurement from iodine-125 brachytherapy sources was done using the spherical ionization chamber of type TM32002 with measuring volume $1 \mathrm{I}$ and the scintillation detector of type BDKR-01M, that registers energy of photon radiation from 3 to $300 \mathrm{keV}$ [16]. The combined result of measurements with two devices which performance is based on different physical principles has an increased confidence level. The calibration coefficients for TM32002 chamber and BDKR-01M detector for iodine-125 were produced by linear interpolation of their calibration coefficients received at the low energy $\mathrm{x}$-rays radiation facility from the structure of GET 8-2011 standard in the energy range from 16 to $33 \mathrm{keV}$.

During the measurement of air-kerma strength from iodine-125 brachytherapy sources TM32002 chamber and BDKR-01M detector were placed simultaneously in the radiation field at the plane perpendicular to the major axis of the source. The measurements were performed at two distances between the source and TM32002 chamber (BDKR-01M detector) to evaluate scattering contribution in the results; the source was rotated about its major axis in increments of $45^{\circ}$ to take azimuthal anisotropy of the source into account. The mean of measured values was taken as a result of air-kerma strength measurement from the iodine-125 brachytherapy source.

Air-kerma strength from iodine-125 sources was calculated using the following expressions: $\quad S_{\text {Кик }}=N_{K} \cdot I \cdot d^{2} \cdot k_{\rho} \cdot k_{a t} \cdot k_{s c} \cdot k_{n} \cdot k_{s t} \cdot k_{d}$ for the measurements with the ionization chamber and $S_{\text {Кбд }}=C_{K} \cdot M \cdot d^{2} \cdot k_{a t} \cdot k_{s t} \cdot k_{d}$ for the measurements with the scintillation detector, where $N_{K}$ is the ionization chamber calibration coefficient for 
iodine-125, $\mu \mathrm{Gy} / \mathrm{C}$; $I$ is the mean ionization current of the chamber, $\mathrm{A} ; d$ is the distance from the center of the chamber to the center of the active part of the source, $\mathrm{m} ; C_{K}$ is the scintillation detector calibration factor for iodine-125; $M$ air-kerma rate measured by the scintillation detector, $\mu \mathrm{Gy} / \mathrm{h} ; k_{\rho}$ is the correction for the difference between the air density during the measurements and under the reference conditions; $k_{a t}$ is the correction for airattenuation; $k_{s c}$ is the correction for scattering; $k_{n}$ is the correction for non-uniformity of electron fluence in the air cavity of the chamber; $k_{s t}$ is the correction for stem attenuation; $k_{d}$ is the correction for the decay of iodine-125 during the time of measurements.

Calibration of well-type ionization chambers with electrometers was performed using the sources with measured air-kerma strength. During the measurements the sources were placed inside the well-chambers at the stated depth using special holders.

The expanded uncertainty $(k=2)$ of air-kerma strength from iridium-192 sources measured by TM32005 ionization chamber is less than $2,5 \%$.

The expanded uncertainty $(k=2)$ of air-kerma strength from iodine-125 sources measured by two detectors (TM32002 chamber and BDKR-01M detector) is less than $3,0 \%[16]$.

The expanded uncertainty $(\mathrm{k}=2)$ of well-chambers calibration coefficient for iridium-192 sources is less than $3,5 \%$ and for iodine- 125 sources is less than $4,0 \%$.

\section{Conclusions and perspective of the research}

The elements of metrological support of measurements with iridium-192 and iodine-125 brachytherapy sources are developed by the VNIIM. The measurement accuracy achieved is in compliance with the standard's requirements [1-4].

Development and implementation of special primary standard facilities for air-kerma strength measurement with brachytherapy sources will improve measurement accuracy up to 1,5-2 times.

\section{References}

1. Приказ Минздрава России от 21.02.2014 г. № 81н Об утверждении перечня измерений, относящихся к сфере государственного регулирования обеспечения единства измерений, выполняемых при осуществлении деятельности в области здравоохранения, и обязательных метрологических требований к ним, в том числе показателей точности измерений.

2. МУ 2.6.1.2135-06 Гигиенические требования по обеспечению радиационной безопасности при лучевой терапии закрытыми радионуклидными источниками.

3. ICRU Report 24 Determination of absorbed dose in a patient irradiated by beams of $x$ - or gamma-rays in radiotherapy procedures, 1976.

4. ГОСТ Р МЭК 60731-2001 «Изделия медицинские электрические. Дозиметры с ионизационными камерами для лучевой терапии».

5. A practical guide to quality control of brachytherapy equipment. European guidelines for quality assurance in radiotherapy. - ESTRO Booklet No. 8, 2004.

6. Nath R., Anderson L. L., Luxton G. et al. Dosimetry of interstitial brachytherapy sources: Recommendations of the AAPM Radiation Therapy Committee Task Group No. 43 // Med. Phys., 1995, 22, P. 209-234.

7. IAEA-TECDOC-1274. Calibration of photon and beta ray sources used in brachytherapy. IAEA, 2002.

8. ГОСТ Р МЭК 62467-1-2013 Изделия медицинские электрические. Дозиметрические приборы, используемые в брахитерапии. Часть 1. Приборы, основанные на ионизационных камерах колодезного типа

9. Caswell R., Wambersie A., Cross W. G. et al. Dosimetry of beta rays and low-energy photons for brachytherapy with sealed sources. - ICRU Report 72, 2004.

10. Soares C. G., Douysset G., Mitch M. G. Primary standards and dosimetry protocols for brachytherapy sources // Metrologia, 2009, 46, C. S80-S98.

11. Seltzer S. M., Lamperti P. J., Loevinger R. et al. New National air-kerma-strength standards for ${ }^{125} \mathrm{I}$ and ${ }^{103} \mathrm{Pd}$ brachytherapy seeds // J. Res. Natl. Inst. Stand. Technol., 2003, 108, C. 337-358. 
12. Selbach H.-J., Kramer H.-M., Culberson W. S. Realization of reference air-kerma rate for low-energy photon sources // Metrologia, 2008, 45, C. 422-428.

13. Toni M. P., Pimpinella M., Pinto M. et al. Direct determination of the absorbed dose to water from ${ }^{125}$ I low dose-rate brachytherapy seeds using the new absorbed dose primary standard developed at ENEA-INMRI // Metrologia, 2012, 49, C. S193-S197.

14. Оборин А. В., Виллевальде А. Ю., Трофимчук С. Г. Государственный первичный эталон единиц кермы в воздухе, мощности кермы в воздухе, экспозиционной дозы, мощности экспозиционной дозы и потока энергии рентгеновского и гаммаизлучений // Измерительная техника, 2012, № 8, С. 3-8.

15. Baker M., Bass G. A., Woods M. J. Calibration of the NPL secondary standard radionuclide calibrator for ${ }^{125}$ I seeds used for prostate brachytherapy // Applied Radiation and Isotopes, 2002, 56, C. 321-325.

16. Оборин А.В., Трофимчук С.Г., Виллевальде А.Ю., Яковенко А.А. Измерение мощности кермы в воздухе от микроисточников медицинского назначения на основе радионуклида ${ }^{125}$ | // Медицинская фризика, 2016, № 3 (71). 